\title{
A Retrospective View of Using Translation in Chinese Teaching
}

\author{
Feng-Mei, Chao ${ }^{1} \&$ Qiao-Yu Cai ${ }^{2}$ \\ ${ }^{1}$ Chinese Language Center, Division of Continuing Education, National Taichung University of Education, \\ Taiwan (R. O. C.) \\ ${ }^{2}$ Department of Language and Literacy Education, College of Humanities, National Taichung University of \\ Education, Taiwan (R. O. C.) \\ Correspondence: Qiao-Yu Cai, Department of Language and Literacy Education, College of Humanities, National \\ Taichung University of Education, Taichung City 40306, Taiwan (R. O. C.). Tel: 886-4-2218-3826.
}

Received: October 22, 2018; Accepted: November 12, 2018; Published: December 18, 2018

The research is financed by the 2018 Adult Basic Education Grant of Education Bureau, Taichung City, Taiwan (R. O. C.).

\begin{abstract}
For non-native Chinese speaking adult immigrants, learning Chinese as a second language with the help of translation is cognitively natural. Such learners, already versed in their mother tongue, can well justify themselves to have "the ability to move appropriately between languages" when translation can be seen as a natural language skill to use, often being used with these learners' scant awareness. Moreover, what goes on in learners' mind is an on-going process that not only draws on analytical and associative resources but also a more elaborated analysis of the new input in an effort to turn the input into intake. Meanwhile, translation is a communicative tool that both the teacher and students find it practical to use in a class. Understanding how to maximize this tool to enhance learners' learning becomes indispensable. The present investigation focuses on classroom observation of two classes where non-native speakers of different proficiency take Chinese lessons for three months. Both teacher-learner and learner-learner interaction indicates translation is a handy medium that learners use to assist learning a new language. Learners with the same language background readily use their mother tongue to help one another grasp the linguistic concepts under study. Other than that, English serves as a common denominator for the interaction between a teacher and his/ her learners.
\end{abstract}

Keywords: translation, Chinese teaching, non-native Chinese speaking immigrants

\section{Introduction}

For non-native Chinese speaking adult immigrants, learning Chinese as a second language with the help of translation is cognitively natural. Such learners, already versed in their mother tongue, can well justify themselves to have "the ability to move appropriately between languages" (Malmkjaer, 1998: 8) when translation can be seen as a natural language skill to use, often being used with these learners' scant awareness. Moreover, what goes on in learners' mind is an on-going process that not only draws on analytical and associative resources but also a more elaborated analysis of the new input in an effort to turn the input into intake (Wilss, 1996; Kallkvist, 2008). Meanwhile, translation is a communicative tool that both the teacher and students find it practical to use in a class. Understanding how to maximize this tool to enhance learners' learning becomes indispensable. The present investigation focuses on classroom observation of two classes where non-native speakers of different proficiency take Chinese lessons for three months. After taking a placement test, learners are assigned to two classes: "advanced" and "beginning". Beginners use Basic Chinese; advanced learners Business Chinese: Advanced. Classroom observation is the key framework in describing the two classes under present study.

\section{Literature Review}

Both teacher-learner and learner-learner interaction indicates translation is a handy medium that learners use to assist learning a new language. Learners with the same language background readily use their mother tongue to help one another grasp the linguistic concepts under study. Other than that, English serves as a common denominator for the interaction between a teacher and his/ her learners. Generally speaking, learning another language via translation is believed to be beneficial. However, one question that is worth asking is what kind of 
teaching method involving translation better allows a teacher to maximize this tool - translation - to help non-native speakers of Chinese to learn this new language as a second language.

One perspective from translation-related literature review on second language acquisition sees translation as "a judicious use of translation" instead of the conventional view of "Grammar-Translation Method (GTM)" (Guan, 2012). GTM is a teacher-centred teaching approach; students do what the teacher tells them to learn (Larsen-Freeman, 2011). Learning mainly involves students' translating readings in the target language into their mother tongue. In order to do so, vocabulary and grammar are of great importance. Hence, a large portion of classroom activities centres on mastering grammatical rules and memorizing lists of target language vocabulary words and their native language equivalents. On the other hand, "a judicious use of translation" emphasizes a task-based approach; students are provided with a natural context to use the target language. According to Guan (2012), a cautious incorporation of translation in completing a real-world task can motivate students in learning and enable teachers to make a critical appraisal of the outcome of such intervention in language teaching. Table 1 is a summary of the characteristics of both approaches.

Table 1. A summary of the characteristics of a judicious use of translation and GTM

\begin{tabular}{|c|c|}
\hline "A judicious use of translation" & Grammar-Translation Method (GTM) \\
\hline $\begin{array}{l}\text { Real-world tasks increase learners' interaction and } \\
\text { expose them to the complicated translation process. }\end{array}$ & $\begin{array}{l}\text { The purpose of learning a foreign language is to } \\
\text { develop the ability to read literature written in it. }\end{array}$ \\
\hline $\begin{array}{l}\text { Translation is part of the cognition for second language } \\
\text { learners, particularly beneficial for those who share the } \\
\text { same native language. }\end{array}$ & $\begin{array}{l}\text { Translation serves as a good mental exercise, } \\
\text { contributive to learners' mental development. }\end{array}$ \\
\hline $\begin{array}{l}\text { Translation-induced links between the native language } \\
\text { and the target language may enhance retention in } \\
\text { memory. }\end{array}$ & $\begin{array}{l}\text { Learners should commit to memory the target } \\
\text { grammatical rules and paradigms, vocabulary and their } \\
\text { native language equivalents. }\end{array}$ \\
\hline $\begin{array}{l}\text { This approach is suitable for learners with a bent for } \\
\text { analysis and advantageous in clarifying certain complex } \\
\text { grammar rules. }\end{array}$ & It's essential to learn grammar rules and vocabulary. \\
\hline $\begin{array}{l}\text { Learners take notice of accuracy, start to use complex } \\
\text { structures, and become aware of similarities and } \\
\text { differences in languages and cultures. }\end{array}$ & $\begin{array}{l}\text { The teacher needs to make sure that students get } \\
\text { correct answers. }\end{array}$ \\
\hline $\begin{array}{l}\text { Introverted and advanced second language learners may } \\
\text { benefit the most. }\end{array}$ & $\begin{array}{l}\text { Reading and writing override speaking and listening as } \\
\text { the skills to be mastered. Little interaction between } \\
\text { students is expected. }\end{array}$ \\
\hline
\end{tabular}

In Guan's discussion (2012), he marries task-based approach up with his teaching Business Chinese in both upper-intermediate and low-advanced classes. Translation is introduced as a task that shares the fundamental instrumental motivation with what a Business course is aimed at. Therefore, each authentic business scenario is paired with a carefully designed translation task which has a focus on particular skills that learners are expected to acquire. In a survey conducted by Guan after years' of practice, a majority of students give positive feedback on learning Chinese through translation tasks. For example, up to ninety percent of students (strongly) agree with the description that says "Translation practice helps me become familiar with a given sentence pattern." Even in the description that has the lowest percentage, eighty-three percent of students (strongly) agree with "Having translation practice helps to effectively improve my Chinese in general."

In addition, students' highly positive feedback in Guan's survey is accounted for by the second point listed in "a judicious use of translation" on translation's being particularly beneficial for those who share the same native language and learn the target language in a non-target language environment. When Chinese is taught as a foreign language as in Guan's case, translation becomes a "natural cognitive process" that goes on in learners' mind. (M. Kallkvist, quoted in Guan 2012) This cognitive advantage, together with elaborate translation tasks, makes a natural shift from what could have been a GTM-characteristic teaching to the task-activated teaching involving translation.

Unlike Guan's students who have the identical first language and learn Chinese as a foreign language in the USA, learners in the present study learn Chinese as a second language in Taiwan. Moreover, they come from different countries speaking their own native languages. Such discrepancies ineluctably require some new thinking of the task-based approach with a dash of a judicious use of translation. 


\section{Research Method}

The main method used in the present study is observation. What characterizes this study is that the researcher herself has the first-hand opportunity to gather "live" data from naturally occurring situations. Data collected include sentences that have errors in them, sentences that are questions asked by students, and sentences that are produced out of students' using their mother tongue as the template to generate the target language.

In addition, the researcher's role in this study leans towards a "complete participant" (Cohen, Manion, \& Morrison, 2011, pp. 465). That is, the researcher conceals herself as an observer, observing the learning process for a short period of time of three months and attempting to gather "thick descriptions" (pp. 468) of the majority of interaction in the classroom.

\section{Classroom Observation}

Learners' background, teaching materials, interactions in the class, and an overall pedagogical implication are treated at great length in the following paragraphs.

\subsection{Advanced Class}

Learners come from seven countries: Vietnam, Thailand, Taiwan, Russia, Holland, Japan, Italy, and Kyrgyz Republic. A large proportion of learners are Vietnamese, up to seven in number. There are two Taiwanese, two Thais, and one from the rest of the countries. They are adult learners, aged between twenty-five and fifty-five years old. The majority of them are working, doing jobs such as teaching at kindergarten or university or working at a company. Few of them are graduate students or housewives. Eighty percent of them are married and have a household in Taiwan; their spouses are either Taiwanese or Chinese living in Hong Kong or China. It is likely that communication with family members, colleagues, and friends is the main drive in learning Chinese.

The main material for advanced learners is Globe Business Chinese II: Advanced, a textbook developed by a teaching material research team in National Taichung University of Education. According to the feedback in a study on the use of digital "Business Chinese" in teaching, non-native learners find dialogue-based texts practical, a role-play based on business negotiation interesting, and the proficiency level suitable for upper-intermediate learners. (Liu, et al. 2014) Besides, it is recognized that Business Chinese itself serves a clear and practical purpose when it is used in teaching. The teaching goal is to give learners a real-world rehearsal of variegated business events. As a consequence, a tasked-based teaching infused with translation exercises in a Business Chinese course will be favourable to adult learners whose mature cognition allows them to harness this capacity to compare and contrast, to analyze, and to internalize the newly acquired knowledge.

The advanced learners in the present study are learning Chinese as a second language. That is to say, the opportunity to expose themselves to Chinese outside the classroom is omnipresent. A good amount of exposure to use Chinese implies that what goes on subconsciously in each learner's mind may have been a constant decoding between their first language and the target language. Nonetheless, in a classroom scenario, the English-dominant translation intervention can be somewhat knotty, especially when learners do not share the same first language. The initial observation of the learners under study indicates that they have a high motivation to learn Chinese; as a result, teaching with Chinese-only strategy is highly welcome. Apart from learners' motivation, only one or two learners seem to feel comfortable and competent enough to learn Chinese through teacher's English explanation. When encountering difficult linguistic items, these learners adopt learning strategies listed as follows:

1. Learners with Chinese proficiency higher than their peers will use their common native language to help each other.

2. One or two outspoken extroverted learners will initiate a discussion with the teacher in Chinese to clarify meaning or usage, and soon enough the clarification process involves other learners to ask and respond.

3. Learners with good English ability, when interacting with the teacher or other classmates, often choose Chinese to communicate, even though they are more acceptable to the teacher's use of English to explain.

Taken together, the observations illustrate that these advanced learners have a clear goal in their learning: to learn and to communicate in Chinese. Translation is spotted when learners resort to their common native language such as Vietnamese or Thai to learn the target language. Chinese, rather than English, often underpins the primary communication between learners speaking different native languages. It is only when both parties stumble over their dialogue while using Chinese, then English is the intervention the teacher uses to help both parties to carry on the task at hand. 


\subsection{Beginners' Class}

Learners come from eight countries: Thailand, America, France, Russia, Vietnam, Mongolia, Japan, and Poland. There are three Thai learners and one from each country. These adult learners are aged between twenty-one and forty-five. Six of them have a job in Taiwan and the other four younger learners are either studying at the graduate school or planning to start the undergraduate study soon. Being in a second language environment, they believe being able to communicate in Chinese is all they need to function well in life, work, or study.

Basic Chinese is a textbook designed for learners with a beginning level. Its current edition is bilingual in Chinese-Thai. The Chinese-English version is not yet available when classes begin, so learners rely on the teacher to use English as the intervention to explain vocabulary, sentence patterns or dialogues. Other than that, Chinese is used throughout lecture sessions.

Due to the fact that Thai instead of English is the "auxiliary" language used in the textbook to cater to Thai learners, classroom observation reveals that most learners feel comfortable to listen to the teacher's lecture in English on their first learning of a new lesson in order to grasp the materials they are studying. Other than English, Chinese is the fundamental means for classroom interaction. Two patterns emerge in the way learners interact with one another.

1. Asian learners with the same native language instinctively code-switch between their L1 and Chinese, much the same as what the advanced learners do. Western learners resort to English to assist their own understanding.

2. English intervention is mainly used by the teacher to make sure learners follow teacher's stepwise guidance through each lesson, such as which paragraph or page to turn their attention to, or the steps of the task they need to know to complete it with a partner. The other occasion for English intervention is answering learners' real-time questions during lecture. Otherwise, Chinese is used to assist learning.

To sum up, Asian learners are not shy of making the most use of Chinese to learn and communicate with the teacher; consequently, they illustrate richer and more diverse Chinese expressions. On the other hand, learners from the western world would choose English as the primary medium to ask or to clarify what the teacher just said. They appear to take fewer risks at using Chinese than the Asian peers. A closer look at teacher-learner or learner-learner interaction indicates that much of the interaction is supported by "scaffolding", a concept central to Vygostsky's view on how a learner can achieve their potential development with assistance. (Saville-Troike, 2012) In a typical teacher-learner interaction, the teacher is the expert who provides learners with chunks of talk that allows learners to use to express concepts that are beyond their independent means. Likewise, in a learner-learner interaction, what is often observed is peers collaborate in constructing language that goes beyond the competence of any individual among them. Moreover, the automatic attitudes these learners show underlines an essential feature of how scaffolding works - the learners being the active participants.

\section{Conclusion}

The so-called Chinese-English translation observed in the two classes under study is manipulated by the teacher to guide learners' learning. The L1-Chinese translation is found when learners directly interact in way to help each other understand the newly taught vocabulary, sentence patterns, and dialogues, an interaction that often serves not only as a problem-solver between learners but also as a springboard for in-depth discussion on a linguistic issue that learners are interested in knowing more. Stibbard (1998), in his argument of using one's first language being a valuable source in developing a leaner's foreign language learning, advocates a "principled use of translation in the classroom" (pp. 72). His justification of using translation also points out the affective-humanistic aspect of reducing learners' anxiety in the process of language learning. Recognizing learners' use of their mother tongue as a sign of the lack of the linguistic resources in the second language to express what they want to say, the teacher can use such a signal as a way to supplement the knowledge gap, which may lead to much discussion and extension to areas of culture and linguistic convention. Therefore, in a broad view of "judicious use of translation", a sound pedagogical approach in the placement of learners before a new class begins should take into consideration learners' L1 and their English proficiency, in addition to their current Chinese proficiency. That is to say, if learners have the common L1 or a common language such as English at the ready, translation no doubt is a natural cognitive process that learners can easily get engaged in. As what Campbell has observed (1998), learning a second language is a process of translation. Besides, what a "judicious use of translation" can aim at is to use task-based translation to intentionally guide and retain students' learning, to sharpen their comprehension, and to increase their ability to use the target language. 
In brief, when learners have imperfect control over the new material they are learning, such as a new language in a second language learning environment, the particular feature of "conversational spoken translation" (Stibbard, 1998: 73) or code-switching arises naturally and becomes prevalent in a bilingual classroom. Instead of being in the pursuit of a product-oriented grammar-translation teaching strategy, bilingualism which sees the potential of translingual interaction in the classroom certainly can shed new light on how to make the most use of learners' mother tongue and the target language in ways that serve the much-desired pedagogical and social functions (Baker, 2006; Martin-Jones \& Jones, 2000).

\section{Acknowledgments}

This research was support by the 2018 Adult Basic Education Grant of Education Bureau, Taichung City, Taiwan (R. O. C.).

\section{References}

Baker, C. (2006). Foundations of bilingual education and bilingualism. Clevedon and Philadelphia: Multilingual Matters.

Campbell, S. (1998). Translation into the second language. New York, NY: Longman.

Cohen, L., Manion, L., \& Morrison, K. (2011). Research methods in education (7th ed.). London and New York: Routledge.

Guan, D. X. (2012). Applications of translation tasks in business Chinese instruction. Teaching Chinese as a Second Language of Taiwan, 12, 6-17.

Kallkvist, M. (2008). L1-L2 Translation versus no translation. In L. Ortega \& H. Byrnes (Eds.), The longitudinal study of advanced L2 capacities (pp. 182-202). New York: Routedge.

Larsen-Freeman, D (2011). Techniques and principles in language teaching (2nd ed.). Oxford: Oxford University Press.

Liu, Y., Chou, C. W., Cai, Q. Y., Yao, L., \& Chen, Y. C. (2014, December). The material design and implementation of business Chinese: A case study of teaching business negotiation to second language learners at Feng Chia University. Paper presented at the 11th International Conference on Teaching Chinese as a Second Language Teaching, National Taipei University of Education, Taipei, Taiwan.

Malmkjaer, K. (1998). Introduction: Translation and language teaching. In K. Malmkjaer (Ed.), Translation and language teaching: Language teaching and translation (pp.1-15). Manchester: St. Jerome.

Martin-Jones, M., \& Jones, K. (2000). Introduction: Multilingual literacies. In Martin-Jones, M., \& K. Jones. Multilingual literacies: Reading and writing different worlds. Amsterdam/Philadelphia: John Benjamins.

Saville-Troike, M. (2012). Introducing second language acquisition (2nd ed.). Cambridge: Cambridge University Press. https://doi.org/10.1017/CBO9780511888830

Stibbard, R. (1998). The principled use of oral translation in foreign language teaching. In K. Malmkjaer (Ed.), Translation and language teaching: Language teaching and translation (pp.69-76). Manchester: St. Jerome.

Wilss, W. (1996). Translation as intelligent behaviour. In H. Somers (Ed.), Terminology, LSP, and translation: Studies in language engineering in honour of Juan C. Sager (pp. 161-168). Amsterdam: John Benjamins. https://doi.org/10.1075/btl.18.15wil

\section{Copyrights}

Copyright for this article is retained by the author(s), with first publication rights granted to the journal.

This is an open-access article distributed under the terms and conditions of the Creative Commons Attribution license (http://creativecommons.org/licenses/by/4.0/). 